\title{
Second Year of Using the Sidekick Basic Kit for TI LaunchPad with Elemen- tary School Students
}

\section{Ms. Tara N. Kimmey, Colorado STEM Academy}

5th/6th grade teacher in Westminster, Colorado. She earned her Bachelor's of Science in Liberal Studies from Longwood University in 2011 with a concentration in Elementary Education. She then went on to earn her Master's of Science in Curriculum and Instruction in Special Education K-12 in 2012.

\section{Dr. Cameron H. G. Wright P.E., University of Wyoming}

Cameron H. G. Wright, Ph.D., P.E., is a Professor with the Department of Electrical and Computer Engineering at the University of Wyoming, Laramie, WY. He was previously Professor and Deputy Department Head in the Department of Electrical Engineering at the United States Air Force Academy, and served as an R\&D engineering officer in the U.S. Air Force for over 20 years. He received the B.S.E.E. (summa cum laude) from Louisiana Tech University in 1983, the M.S.E.E. from Purdue University in 1988, and the Ph.D. from the University of Texas at Austin in 1996. Cam's research interests include signal and image processing, real-time embedded computer systems, biomedical instrumentation, and engineering education. He is a member of ASEE, IEEE, SPIE, BMES, NSPE, Tau Beta Pi, and Eta Kappa Nu. His teaching awards include the University of Wyoming Ellbogen Meritorious Classroom Teaching Award (2012), the Tau Beta Pi WY-A Undergraduate Teaching Award (2011), the IEEE UW Student Branch's Outstanding Professor of the Year (2005 and 2008), the UW Mortar Board "Top Prof" award (2005, 2007, and 2015), the Outstanding Teaching Award from the ASEE Rocky Mountain Section (2007), the John A. Curtis Lecture Award from the Computers in Education Division of ASEE (1998, 2005, and 2010), and the Brigadier General Roland E. Thomas Award for outstanding contribution to cadet education (both 1992 and 1993) at the U.S. Air Force Academy. He is an active ABET evaluator and an NCEES PE exam committee member.

\section{Dr. Thad B. Welch, Boise State University}

Thad B. Welch, Ph.D., P.E. received the B.E.E., M.S.E.E., E.E., and Ph.D. degrees from the Georgia Institute of Technology, Naval Postgraduate School, Naval Postgraduate School, and the University of Colorado in 1979, 1989, 1989, and 1997, respectively. He was commissioned in the U.S. Navy in 1979 and has been assigned to three submarines and a submarine repair tender. He has deployed in the Atlantic Ocean, Mediterranean Sea, and the Arctic Ocean.

From 1994-1997 he was an Instructor and Assistant Professor teaching in the Electrical Engineering Department at the U.S. Air Force Academy, Colorado Springs, CO. During 1996-1997 he was recognized as the Outstanding Academy Educator for the Electrical Engineering Department.

From 1997-2007 he was an Assistant Professor, Associate Professor, and Permanent Military Professor teaching in the Electrical Engineering Department at the U.S. Naval Academy, Annapolis, MD. During 2000-2001 he was recognized as the Outstanding Academy Educator for the Electrical Engineering Department. During 2001-2002 he received the Raouf outstanding engineering educator award. During 2002-2003 he was recognized as the Outstanding Researcher for the Electrical Engineering Department. He was an invited scholar at the University of Wyoming, fall 2004, where he was recognized as an eminent engineer and inducted into tau beta pi. In 2006 he co-authored "Real-time Digital Signal Processing, from MATLAB to C with the TMS320C6x DSK" which was translated into Chinese in 2011. The second edition of this text was published in 2012 and the third edition was published in 2017.

From 2007-2010 he was Professor and Chair of the Electrical and Computer Engineering Department at Boise State University, Boise, ID. From 2011-2012 he was the inaugural Signal Processing Education Network (SPEN) Fellow. From 2012-2014 he and his wife lived with 20 engineering students in the engineering residential college (ERC) on the Boise State campus.

His research interests include real-time digital signal processing (DSP), the implementation of DSP-based systems, and sustainable energy systems. 


\title{
Second Year of Using the Sidekick Basic Kit for TI LaunchPad With Elementary School Students
}

\begin{abstract}
$\underline{\text { Abstract }}$
This paper describes a second year, follow-on study in which $4^{\text {th }}$ and $5^{\text {th }}$ grade students were exposed to engineering-related topics using a microcontroller, input/output circuitry, sensors, and the associated software coding needed to achieve a desired functionality of the hardware. The first year study was described in a paper presented at the 2017 ASEE Annual Conference. This second year study took students to the "next level," and showed very promising results.
\end{abstract}

\section{Introduction}

Exposure to STEM topics for Americans has been a widely accepted goal for many years [1], and early exposure in K-12 is certainly desirable and becoming more prevalent. For example, a recent Gallup poll found that exposure to software coding in K-12 increased from $25 \%$ of the schools surveyed in the 2014-2015 school year to 40\% in the 2015-2016 school year [2]. Other efforts, such as the "Hour of Code," have also shown some promising results [3]. Such early exposure to STEM topics should better motivate students to pursue engineering in college, and could help more students succeed in an engineering curriculum.

Although the Sidekick basic kit for TI LaunchPad ${ }^{\mathrm{TM}}$ is intended for a much more experienced group of students, engineers, and makers, we introduced it last year to four classes of $5^{\text {th }}$ grade elementary school students. From here forward, we will refer to the Sidekick basic kit for TI LaunchPad ${ }^{\mathrm{TM}}$ as The System. Results from the first year of the project, which included experiments and software coding, were very promising:

1. 85 out of the 98 students felt that they could perform the experiment by themselves, and

2. 57 of the 98 said they could successfully code without help from a partner.

These first-year results were presented at the 2017 ASEE Annual Conference [4] and later published in expanded form in a journal [5].

The goal of using The System was to allow the students to develop the skillset necessary to create a series of projects that utilize light emitting diodes (LEDs) and a moisture sensor. These projects fit well within the existing $4^{\text {th }}$ and 5th grade Next Generation Science Standards (NGSS) Curriculum [6].

For this second year of the project, we added the use of TI SensorTagsTM to help the students take the "next step" in their moisture tests. That is, they not only write code for the TI LaunchPad $^{\mathrm{TM}}$ to use LEDs, but they also use Bluetooth-compatible TI SensorTags ${ }^{\mathrm{TM}}$ to help with recording their findings on a computer data system. 
Similar to last year, once the students understood how The System functioned, they developed and began testing a series of systems to measure the moisture content of the air at a number of different locations around their school. These systems recorded moisture data for subsequent analysis. This was all facilitated by using the system to:

- discuss and explore open and complete circuits;

- explore inexpensive microprocessors (Integrated USB 2.0-enabled MSP430F5529 16-bit MCU, 40-pin interface, 28KB Flash, 8KB RAM, 25MHz CPU speed);

- create simple programs based on a wide variety of available Energia software example projects; and

- offer a wide variety of loose components, wires, and breadboards to complement followon experimentation and discovery.

Due to the overwhelming success of the project last year, the project was continued for a second year. Starting in September, 80 students were given a five question pre-assessment (see Appendix). Specifically, 45 students were $4^{\text {th }}$ grade equivalent, and 35 students were $5^{\text {th }}$ grade equivalent (note that this is a competency-based school that uses Marzano's Levels, where Levels 4 and 5 equate to the more traditional 4th and 5th grades; the Level 4 and Level 5 students are mixed together in three different classes). The assessment asked students how comfortable and confident they were with coding. The first-named author teaches at a well-recognized STEM Academy in Colorado. At this school, Technology is a class that all students start taking in Kindergarten, so we anticipated a relatively high initial degree of confidence and comfort with coding compared to what one might find in a typical school. Looking at the pre-assessment, $70 \%$ of students (56 of 80 ) ranked themselves with a 3 or better in confidence related to coding/programming for experiments. Furthermore, 51\% of students (41 of 80 ) assessed themselves with a 3 or better for being comfortable in the same area. After taking the preassessment, students were given two different days to explore. On the first day, students were given The System. They had 45 minutes to write down their observations and make predictions on what they believe The System could be used for. On the second day, students were given the TI SensorTags ${ }^{\mathrm{TM}}$ Development Kit. Students continued their brainstorming of the new system.

At this school, Science is a 45 minute class, five days a week. During this time, five $8^{\text {th }}$ graders volunteered to assist us in the classroom for a total of three hours a week. Their main focus was dedicated towards helping develop the students' projects, graphing their data, and improving their coding. After having been given time to exploring the TI LaunchPad ${ }^{\mathrm{TM}}$ and SensorTags ${ }^{\mathrm{TM}}$ Development Kit, students started brainstorming how to create moisture sensors around the school. XXX Academy is a K-8 school that has two different buildings. The first building is a single story with insulated walls that houses the Kindergarten to $5^{\text {th }}$ grade classes. Across the street from the first building is a two-story brick building that is home to $6^{\text {th }}$ to $8^{\text {th }}$ grade. Students decided to deploy five sensors on campus:

Elementary Building

1. Our classroom, $5^{\text {th }}$ grade, which has a boiler room underneath it

2. Main office

3. $3^{\text {rd }}$ grade classroom that is located right next to our track 
Middle School Building

4. Technology room on the first floor

5. $6^{\text {th }}$ grade classroom on the second floor

Students selected \#1 because the classroom does not sit directly on the ground, and has a warm room underneath. Location \#2 was selected because it is a neutral location, but the front of the school is always colder. Location \#3 was selected because it has large windows and is sitting directly on the ground. Location \#4 and \#5 are classrooms that are on top of each other. The Middle School Building does not have circulating heat. The building is always very hot or cold, depending on the day. Students hypothesized that the most moisture would either be in locations \#1 or \#5. Students wrote persuasive essays in Language Arts to help support their hypothesis.

\section{Educational Standards}

The educational standards which guided the student activities were taken from the Next Generation Science Standards [6]. In particular, the standards for $4^{\text {th }}$ and $5^{\text {th }}$ grade students which apply directly to this work are shown below.

4-PS3-2. Make observations to provide evidence that energy can be transferred from place to place by sound, light, heat, and electric currents.

4-PS3-3. Ask questions and predict outcomes about the changes in energy that occur when objects collide.

4-PS4-1. Develop a model of waves to describe patterns in terms of amplitude and wavelength and that waves can cause objects to move.

4-PS4-2. Develop a model to describe that light reflecting from objects and entering the eye allows objects to be seen.

4-PS4-3. Generate and compare multiple solutions that use patterns to transfer information.

5-ESS3-1. Obtain and combine information about ways individual communities use science ideas to protect the Earth's resources and environment.

\section{Technology Use}

The System consisted of four main elements, both listed and shown in figures:

1. MSP430 Launchpad Evaluation Kit (see Figure 1),

2. Sidekick Basic Kit for TI LaunchPad (see Figure 2),

3. Grove Base Booster Pack (see Figure 3), and the

4. Grove Starter Kit for Launchpad (see Figure 4). 


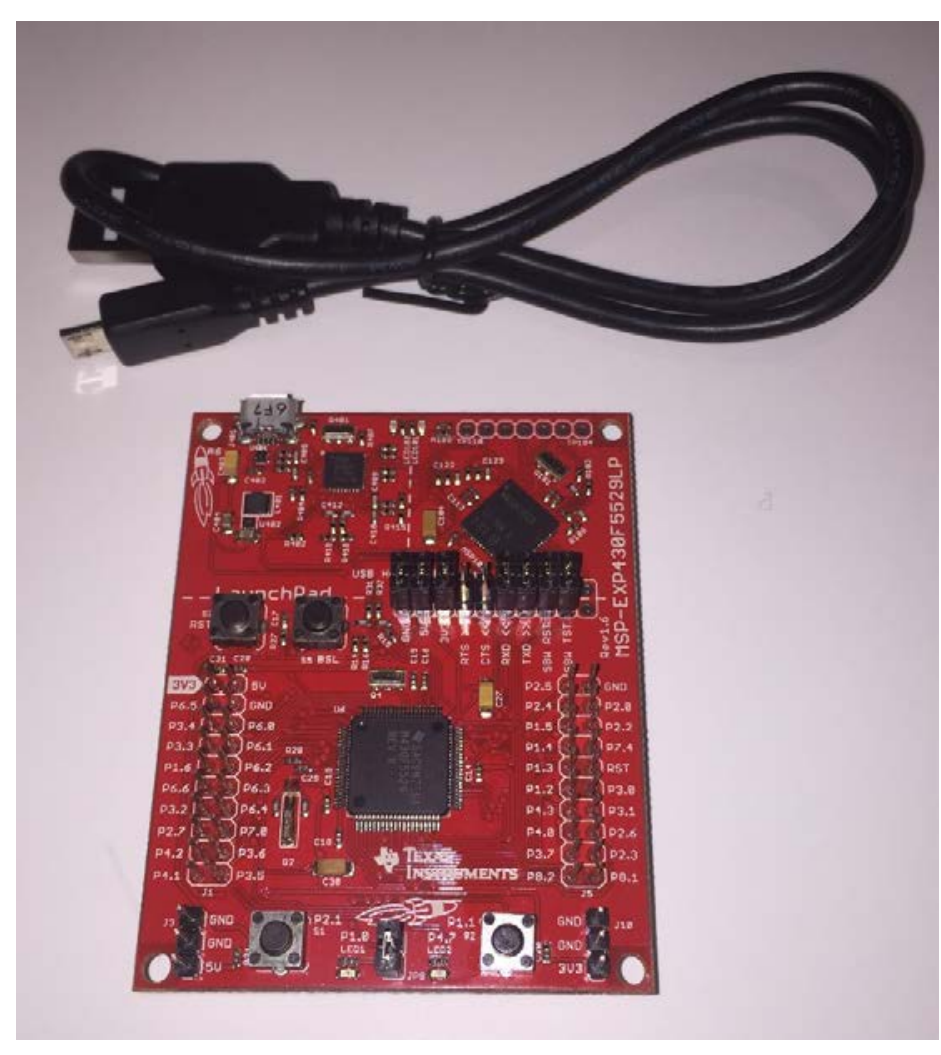

Figure 1. MSP430 Launchpad Evaluation Kit

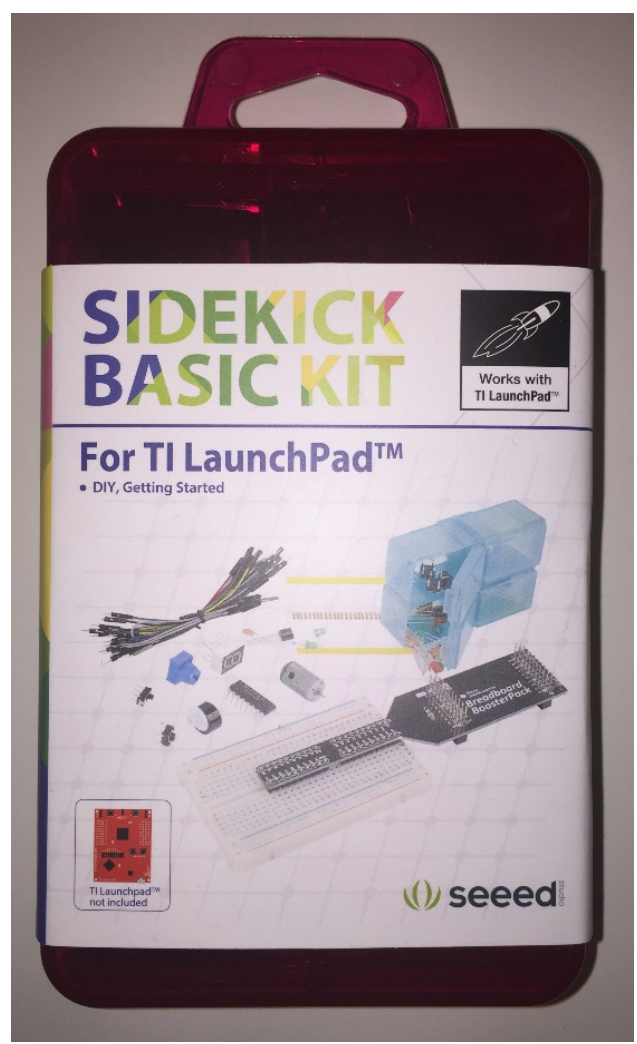

Figure 2. Sidekick Basic Kit

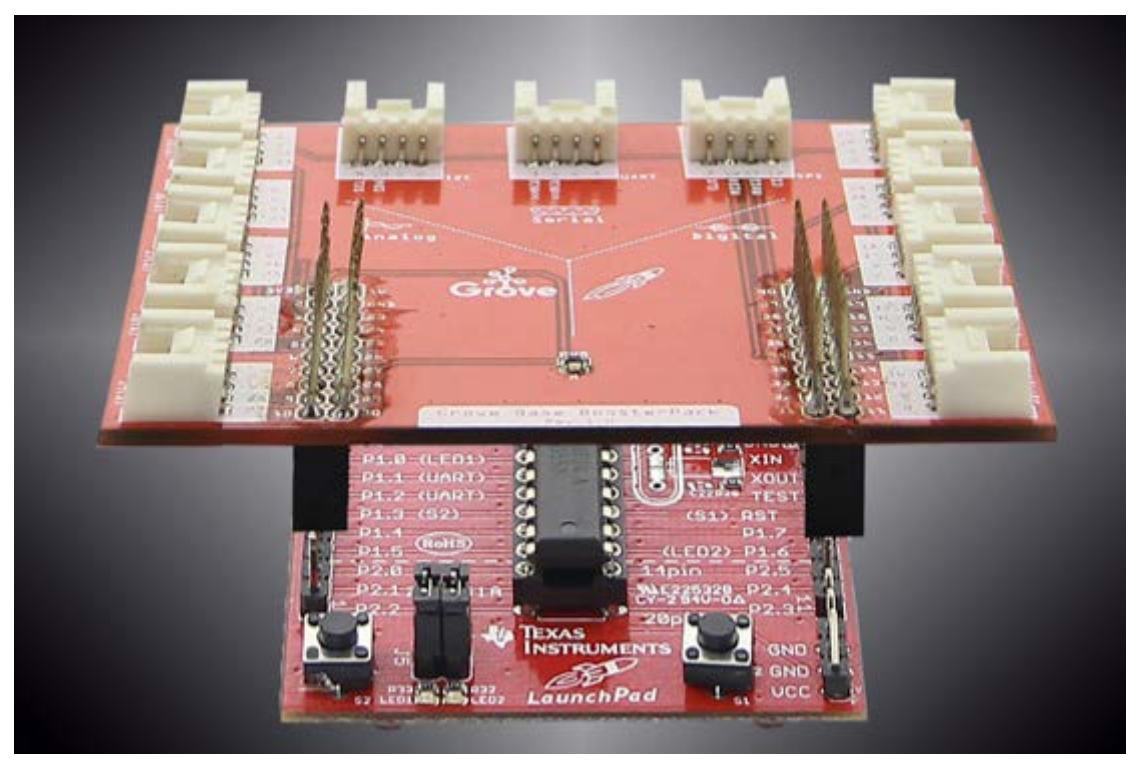

Figure 3. Grove Base Booster Pack 


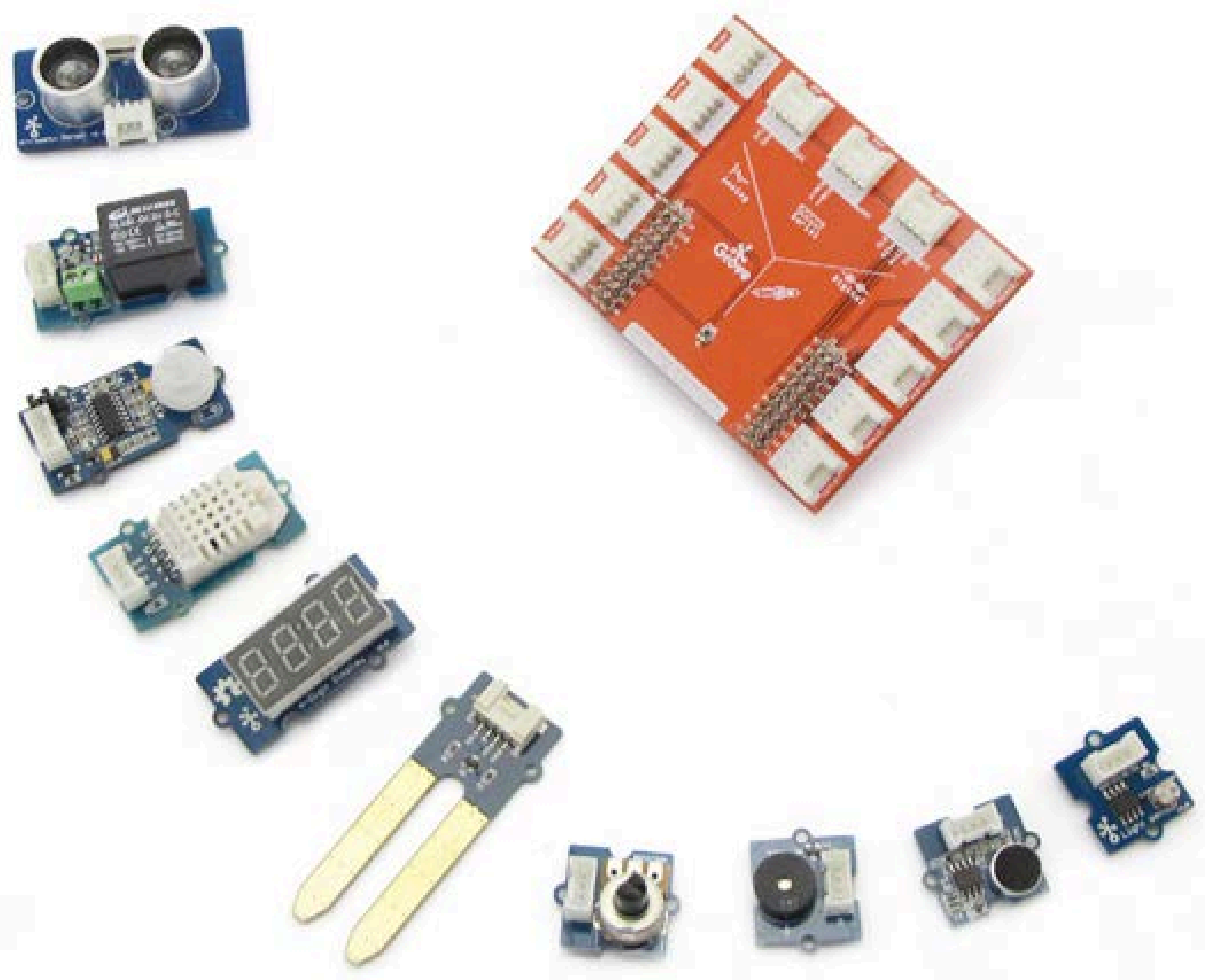

Figure 4. Grove Starter Kit for Launchpad

The addition to the project this year was the TI SensorTags ${ }^{\mathrm{TM}}$ Development Kit, which includes a low-power SimpleLink Wi-Fi CC3200 wireless MCU (TI describes this as the industry's first Wi-Fi CERTIFIED ${ }^{\mathrm{TM}}$ single-chip microcontroller unit (MCU) with built-in Wi-Fi connectivity). The Wi-Fi SensorTag kit includes 9 low-power MEMS sensors.

\section{Projects and Results}

The first few weeks were used to help the students understand the different components of The System and The TI SensorTags ${ }^{\mathrm{TM}}$. The students were provided hands-on experiences with the probes, screw terminals, input analog source, test points, and the different interfaces. As they progressed, they made closed circuits which resulted in lighting an LED board through user push buttons. The Grove Starter Kit allowed the students to explore: a buzzer, 4-digital display, a relay, passive infrared (PIR) sensor, an ultrasonic ranger, light sensor, rotary angle sensor, sound sensor, moisture sensor, and a temperature humidity sensor. The TI SensorTags ${ }^{\mathrm{TM}}$ allowed students to use Bluetooth technology and show coding in an online app. 
Over a course of six months, students were given real-life problem-based learning (PBL) projects to help with their knowledge and application. Some projects lasted a week, while others lasted over a month. Some projects built on a previous project, while others were completely independent. At first, students were slowly introduced to the coding component. They spent about two hours a week working on programs and exploring the different modules that each of the systems allowed. The $8^{\text {th }}$ graders were used to help with this portion. Although they were learning coding as well, they were able to help students that needed extra support.

The first PBL project related to a discussion on insulation and energy within the classrooms. Students were tasked to make the most light- and sound-efficient classroom. Due to our campus spanning two different buildings, students were able to quickly hypothesize as to which building would be the best to start doing research on. Students took The System and had one week to run tests around the two different buildings. Their tests were focused on which locations had the most moisture. From those findings, they then had to do more research about how the individual rooms and the building were insulated. Students were able to take their data, and use that as a driving force to make their scale model classrooms.

Each moisture sensor was read through a 4-digit display and a 10-LED display array. Any 4-digit display reading above 600 would lead to all 10 LEDs being illuminated. For our purposes, the more moisture in the air, the more LEDs would turn on. There was a 0.2 second delay from when the moisture sensor was in contact with the water, to when it would read on the 4-digit display. When the moisture sensor was submerged in water, the 4-digit display read 620 .

As an addition to the scale models, students had to work on insulating the walls of the models of the classrooms they created. They conducted research on how to keep heat inside while repelling the cold. Students found that the most moisture was in Location \#1, due to the boiler room being located directly underneath. They found the least moisture was in Location \#4. They concluded this was due to location \#4 being on the first floor of a building that does not have any circulating heat. Once the scale models were created and presented, students placed the Sensor Tags in each one of the classroom models. These models were then placed outside. During the course of a week students were able to read data to see which classroom would be the best to insulate heat while keeping the moisture out.

Results of the post-assessment survey showed that both confidence and the level of comfort related to coding/programming for experiments grew significantly.

1. $90 \%$ of students (72 of 80 ) ranked themselves with a 3 or better in confidence.

2. $85 \%$ of students (68 or 80 ) assessed themselves as a 3 or better for comfort.

The growth from pre-assessment to post-assessment is shown graphically in Figure 5. 


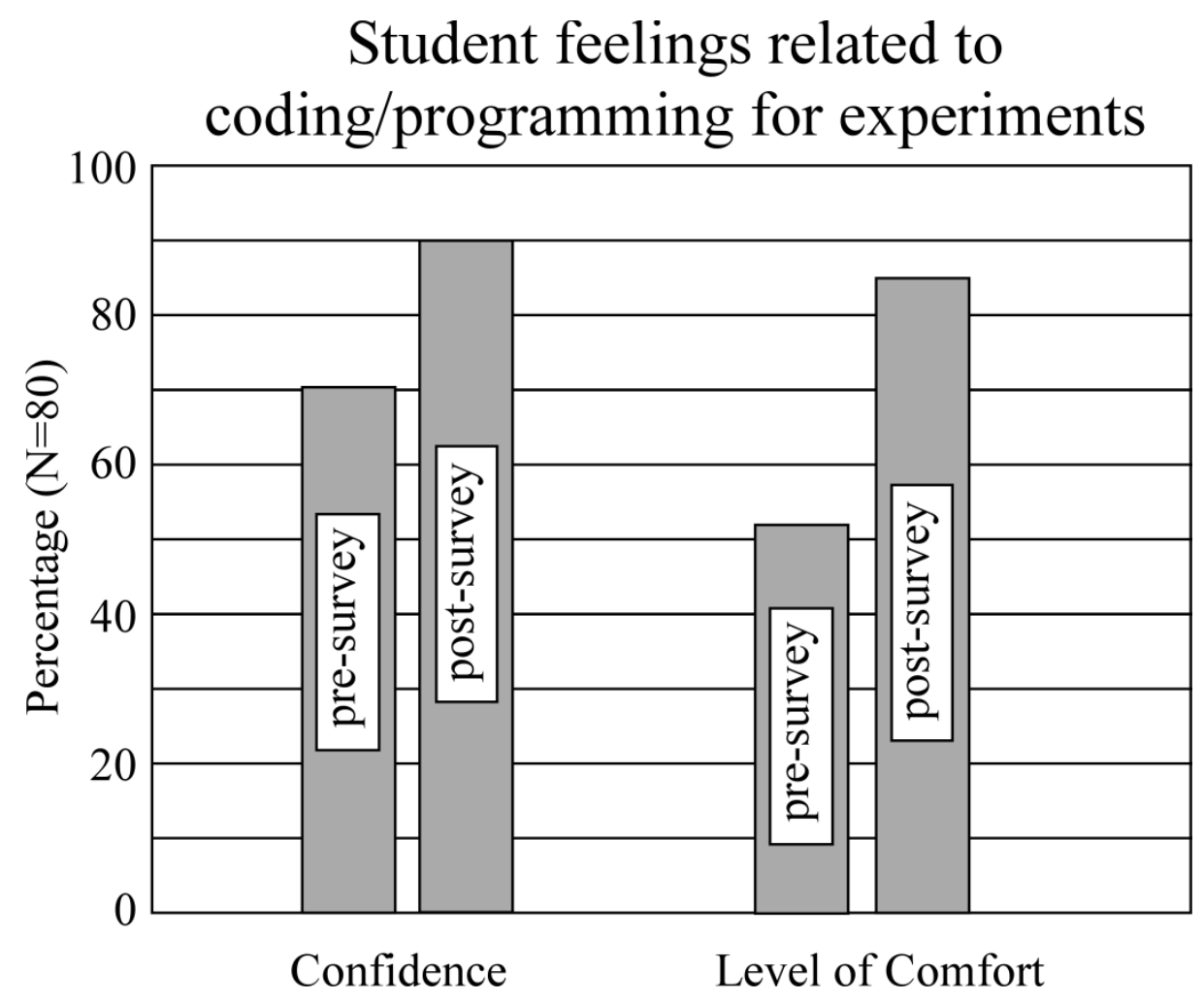

Figure 5. Growth in feeling of confidence and comfort related to coding/programming for experiments. Percentage shown is for students who ranked themselves as a 3 or better on a scale of 1 to 5 , with 1 being not at all confident or comfortable, and 5 being very confident or comfortable.

\section{Conclusion}

The Sensor Tags allowed students to take their light and sound classroom to the "next level." Not only were they able to make predictions and see which of the real classrooms was able to have the most moisture, but they also took their data and created their own scale-model classrooms. Due to this project, students reported significant growth in both confidence and comfort related to coding/programming for experiments. Allowing the students to not only predict and problem solve, but also to take real-world data and create models to test their ideas has proven to be a very powerful approach.

\section{Acknowledgement}

The MSP430 Launchpad Evaluation Kits, the Sidekick Basic Kits, and the SensorTags were provided by Texas Instruments for use in the classroom. 


\section{$\underline{\text { References }}$}

[1] American Association for the Advancement of Science, Science for All Americans, a Project 2061 Report on Literacy Goals in Science, Mathematics, and Technology, 1989.

https://www.aaas.org/report/science-all-americans

[2] Gallup, “More K-12 Computer Science Classes Teach Programming/Coding.” Accessed online: Feb 2018. http://news.gallup.com/poll/196511/computer-science-classes-teachprogramming-coding.aspx

[3] Hour of Code. Accessed online: Feb 2018. https://hourofcode.com/us

[4] XXX, XXX, and XXX, "Elementary School Use of the Sidekick Basic Kit for TI LaunchPad," in Proceedings of the 2017 ASEE Annual Conference, (Columbus. OH (USA)), Jun. 2017. Paper AC2017-19676. [NOTE: author names suppressed for blind review]

[5] XXX, XXX, and XXX, "Elementary School Use of the Sidekick Basic Kit for TI LaunchPad,” Transactions on Techniques in STEM Education, vol. 2, no. 4, pp. 67-72, JulySeptember 2017. [NOTE: author names suppressed for blind review]

[6] Next Generation Science Standards. Accessed online: Feb 2018.

https://www.nextgenscience.org/

\section{$\underline{\text { Appendix }}$}

The next page provides the instrument used for the pre-and post-assessment of the $4^{\text {th }}$ and $5^{\text {th }}$ grade students. 


\section{Coding Project Assessment}

Directions. Please answer the following questions to the best of your ability.

1. Have you ever had exposure to a coding/programming project before? Yes No If "yes", what kind:

2. Can you code by yourself without assistance from a teacher or partner? Yes No

3. Rate yourself $1-5$ with how comfortable you feel completing a coding/programming experiment by yourself? ( 1 not at all -5 very confident)

$\begin{array}{lllll}1 & 2 & 3 & 4 & 5\end{array}$

4. Rate yourself $1-5$ with how confident you feel with coding? ( 1 not at all -5 very confident)

$\begin{array}{lllll}1 & 2 & 3 & 4 & 5\end{array}$

5. What is coding and/or programming? 